\title{
DETALLES DE LA CRITICA LITERARIA CUBANA
}

\author{
POR \\ JOSE PRATS SARIOL \\ UNEAC
}

Por desgracia, difícil es decir y pensar lo que es justo; sin grave ofensa del Estado, los dioses y costumbres.

(GOETHE, Epigramas venecianos)

La literatura circunstanciadamente encara las dificultades que Goethe resumiera quizá al pie de la Escalera de los Gigantes del Palazzo de los Dux, donde antaño decapitaban... La crítica literaria enfrenta, por supuesto, la misma vocación. El reto, matizado por sistemas sociales, épocas y países o culturas, no es una entelequia. La función del crítico implica, hasta eludiéndolas, muy concretas responsabilidades. También criticar las críticas de los críticos rebasa el juego de palabras.

Ofrecer algunos detalles cubanos, de la llamada posvanguardia al eclecticismo discernido de hoy, será el objeto de estas líneas. La señal es hacia una reflexión sobre el oficio, una somera caracterización y un golpe de vista al nuevo siglo, si la demencia nuclear y ecológica permite recibirlo. Quizá la intención sea dar una «política del espíritu» y aspirar — tan irónicamente como Monsieur Teste- a que «la bétisse n'est pas mon fort».

Este medio siglo de crítica literaria en Cuba lleva consigo una gratitud, además de las gratuidades e ingratitudes que suelen acompañar nuestro trabajo en cualquier latitud. La continuidad histórica, si la frase no alimentara tan variadas reticencias, parece diáfana, aun considerando momentos de voces, algarabías o silencios desde nuestro precario neoclasicismo de finales del siglo XVIII, sin flagrantes miopías deterministas y sin dislocados chauvinismos.

Para el detalle del oficio he tomado como referencia a José Lezama 
Lima. Sus apuntes sobre el ejercicio del criterio, dispersos en su obra ensayística y narrativa, así como en múltiples entrevistas, son de una lucidez sin deslumbramientos, sin obviar la gracia o la maldad de algún desliz no compartible.

En el capítulo IX de Paradiso, José Cemí interrumpe a su amigo Fronesis, que hablaba sobre el Quijote, para decir:

La crítica ha sido muy burda en nuestro idioma. Al espíritu especioso de Menéndez y Pelayo, brocha gorda que desconoció siempre el barroco, que es lo que interesa de España y de España en América, es para él un tema ordalía, una prueba de arsénico y de frecuente desbarro. De ahí hemos pasado a la influencia del seminario alemán de filología. Cogen desprevenido a uno de nuestros clásicos y estudian en él las cláusulas trimembres acentuadas en la segunda sílaba. Pero penetrar a un escritor en el centro de su contrapunto, como hace un Thibaudet con Mallarmé en su estudio, donde se va con gran precisión de la palabra al ámbito de la Orplid, eso lo desconocen beatíficamente.

La opinión, a la que más de veinte años después habría qu añadirle otros seminarios y escuelas, parece útil como advertencia, aunque ro deje de exhibir ciertos goterones de subjetividad hiperbólica. La búsqueda de la Orplid, ese tránsito por las palabras hacia un centro, constituye el axis del oficio. Claramente, tales encuentros - en la crítica cubana o en la argentina o en la norteamericana - son raros, esporádicos y no siempre verificables. Recordar labores como las realizadas por José C. Mariátegui, Alfonso Reyes y Pedro Henríquez Ureña, o admitir como un hito el estudio de Amado Alonso sobre Neruda, o las investigaciones sobre sociología de la literatura latinoamericana iniciada por Angel Rama y por Alejandro Losada, siempre tendrá saludables polémicas.

Para evitar catálogos de autores y obras, ya elaborados por los excelentes referencistas de la Biblioteca Nacional José Martí, he decidido reducir al mínimo los ejemplos. Los ahorros, incluyendo malevolencias y «asociaciones de bombos mutuos», son obvios. Por ello, baste citar, entre los autores desaparecidos, a Juan Marinello, José María Chacón y Calvo, Medardo Vitier... Libros como La cantidad hechizada, de José Lezama Lima, y Tientos y diferencias, de Alejo Carpentier... Estudios como el realizado por Mirta Aguirre sobre la «Elegía a Jesús Menéndez», de Nicolás Guillén; el de Virgilio Piñera, «El secreto de Kafka», o el de Luis Rogelio Nogueras sobre la novela policial... Recordar a profesores como Raimundo Lazo, Mario Rodríguez Alemán...

En un ensayo de 1941 sobre «Julián del Casal», Lezama apuntaba: «Así, por ese olvido de estampas esenciales, hemos caído en lo cuantitativo 
de las influencias, superficial delicia de nuestros críticos, que prescinden del misterio del eco. Como si entre la voz originaria y el eco no se interpusieran, con su intocable misterio, invisibles lluvias y cristales.» $\mathrm{Y}$ abogaba por un «razonamiento reminiscente» para evitar un «desteñido complejo inferior». El poeta de Fragmentos a su imán no sólo se adelantaba a lo que después sistematizarían algunas tendencias de la crítica actual, como la que encontramos en la obra de Jacques Derrida, sino que ponía la flecha en un blanco común. Excepciones como Lo cubano en la poesía, de Cintio Vitier, o La expresión americana, de Lezama Lima, ciclos de conferencias pronunciadas en La Habana de 1957, no cubren la presencia de abundantes estudios sin el «misterio del eco», en particular textos panorámicos o pretendidas historias literarias. Si géneros como el teatro pueden mostrar un logro - La selva oscura, de Rine Leal-, otros aún esperan, mientras sí puede observarse - como en el Calibán, de Roberto Fernández Retamar- una acelerada desaparición del «desteñido complejo inferior».

Consciente de que «el estudio de la literatura debe rebasar las fuentes de información que sean estrictamente literarias», como afirmaba en su curiosamente didáctico prólogo a la Antología de la poesía cubana, editada en 1965, Lezama también supo advertir contra el exotismo y exaltar la plenitud ejemplar de José Martí: «Martí vive a plenitud tres posibilidades expresivas del hombre americano: la del barroco, la del romanticismo y la de la autoctonía. Parece estar en el centro mismo de esa triple tradición... Fue suerte inefable para todos los cubanos que aquél que trajo las innovaciones del verbo las supiese encarnar en la historia. Fue suerte también que el que conmovió las esencias de nuestro ser fue el que reveló los secretos del hacer.» En ese sentido de la integralidad y de la integridad se hallan dos signos, dos ariadnas, de nuestra crítica literaria.

La lección ética y científica está también en una conferencia sobre Juan Clemente Zenea, al traernos un hirviente problema de la crítica en el «circuito cultural» cuando declara: «Es el escritorzuelo, el poetastro que busca rubios ditirambos, sitios donde colaborar espumando el cumbilismo, se afana en aparecer en antologías, escribe veinte cartas diarias a personajillos, y al final se encuentra con que su obra no vale una nuez foradada, que nadie le hace eco y termina el rencorete inoculando rabia profesoral domiciliaria.» La abundancia de este espécimen - ayer u hoy, allá o aquíy el consiguiente enrarecimiento» de los ámbitos literarios, se une a la de los «profesionales del aburrimiento», según una de las estampas de Sucesiva o las coordenadas habaneras de 1949-1950, donde Lezama dice que tal «profesional», desde su «nadismo salonnière», «comienza por no hacer nada; sigue por no aceptar que alguien lo puede hacer, y termina en que si alguien lo hace, suda envidia fría y prepara mordiscos de jabalí con 
espuma de arsénico borgiano». No pocos críticos ágrafos, hasta de fantástico o fantasmal prestigio, entorpecen el oficio.

El detalle de la caracterización puede tomar tres ilustraciones significativas. En 1949, desde el Diario de la Marina, Jorge Mañach decía en un artículo «Sobre el menester crítico en Cuba» que «no hay ya apenas crítica en Cuba». Y agregaba «cierta falta de plenitud, de regularidad y de rigor en casi todo ese ejercicio aislado de la crítica», para preguntarse: « ¿Se dirá que no hay crítica literaria porque apenas hay producción? Sin embargo, por aquellos últimos tiempos de la colonia en que se publicaban muy contados libros en Cuba, los Ricardo del Monte, los Armas, los Montoro, los Piñeyro, los Varona y tantos más, a falta de material cubano, enjuiciaban muy continuamente el material extranjero, y ciertamente no se publicaba en la Isla obra literaria de alguna cuenta en que ellos no se fijaran, con indulgencia no exenta de rigor.» $\mathrm{El}$ autor de Indagación del choteo volvía con otra pregunta: « ¿No sería lícito afirmar también, querido José María Chacón, que la actitud puramente descriptiva, cuando no la vaguedad encomiástica y la indulgencia a caño abierto, se sustituyen demasiado al rigor en la poca crítica que tenemos?» Y añadía: «Lee uno por ahí cada elogio desmesurado que lo deja boquiabierto, cada superlativo que da vértigo... Se está creando en Cuba una especie de noche artificial en que todos los gatos son pardos.»

Casi diez años después, desde las páginas de la revista Ciclón, que dirigiera el crítico y traductor José Rodríguez Feo, Virgilio Piñera arremetía contra la «crítica algodonosa». Y en 1969, Juan Marinello, al hablar «Sobre nuestra crítica literaria» en la Universidad de La Habana, afirmaba: «Parece fuera de debate que la crítica de toda manifestación creadora, y singularmente de la literaria, es entre nosotros escasa, intermitente y contradictoria.» Otras ilustraciones y hasta encuestas como la realizada a finales de los setenta por la revista Revolución y Cultura podrían citarse a favor o en contra de las ideas de Mañach, Piñera y Marinello. Sí parece fuera de debate la heterogeneidad de textos escritos durante el período bajo el rubro de crítica literaria. Sería tonto verlo como un rezago y vincularlo mecánicamente al subdesarrollo. Un análisis sistemático, pero que no podría circunscribirse a Cuba, incluiría argumentos como la crisis de la galaxia Gutenberg, la anemia y neurastenia sobre la función de la crítica, la influencia discriminante de algunos absolutismos «científicos», la sencilla carencia de Agudeza y arte de ingenio...

La valoración de nuestra crítica en 1987, a pesar de la insularidad.o de los problemas derivados de la situación política, no puede ordenarse fuera del contexto latinoamericano como parte de un análisis que cada día alcanza una dimensión más universal. Las dificultades específicas, enten- 
didas dialécticamente como metas en las que todos participamos, entre la tolerancia y la disidencia, tampoco dejan de recordar las palabras de Yeats sobre el arte: "Art is a social act of a solitary man.»

Una pizca de optimismo nos permitiría hablar de «crisis de desarrollo» dentro de la aventura de argonautas que debemos cumplir contra hidras y gorgonas que van desde el matorral de la inofensiva retórica hasta la noción del intelectual como amanuense, desde la rutina hasta la docta ignorancia o el embalsamar logros o las jerigonzas o el relativismo apreciativo que la mediocridad con tanto gusto preconiza. Sin contar, para terminar los engorros, con una multiplicación de la «demanda» que como excelente signo de desarrollo se'viene favoreciendo, pero sin preocupaciones eficaces sobre cómo la «oferta» vive y trabaja. La contradicción, nada sencilla, exige rectificaciones audaces, sin burocratismos entorpecedores y sin olvidar que se trata de un país asediado, víctina también del intercambio desigual y de los lastres del subdesarrollo...

La caracterización debe observar, asimismo, cómo en los años iniciales del período conviven y se yuxtaponen tres tendencias: una de corte neopositivista, otra más o menos vinculada al intuicionismo y una tercera de marcada tirantez sociológica con bandazos hacia simplicidades dogmáticas del mal llamado «realismo socialista». La confluencia, bien polémica, se enriquece con la irrupción de la escuela germano-hispana, sobre todo para la crítica de poesía, y a partir de los años cincuenta, del «New Criticism» y de diversas técnicas del llamado «comentario de textos». A partir de 1959 y hasta los primeros años de la década del setenta, el panorama se mantiene dentro de esa heterogeneidad. De entonces a hoy irrumpen las informaciones sobre nuevas corrientes de un modo menos caótico, desde una nueva (o verdadera) estética marxista sin sociologismos vulgares, hasta tendencias estructuralistas y semióticas. La repulsión a cualquier vicio idealista o dogmático, a sectarismos anquilosantes o hipertrofias de algún instrumental, parece lograr unanimidad, dentro de un panorama sin ortodoxias rígidas. Los mejores textos de teoría, crítica e historia literarias publicados desde 1980 a hoy dan fe inequívoca de favorables evoluciones. Nuevas revistas especializadas como Criterios, Revista de Literatura Cubana, Letras Cubanas..., junto al concurso Mirta Aguirre de crítica literaria y las recientes becas Razón de Ser que otorga el Centro de Promoción Cultural Alejo Carpentier, ejemplifican a favor de un clima que paulatinamente debe tender a mejorar, sobre todo si las valoraciones se desprenden de entidades e instituciones y van más a cada crítico, a su labor concreta.

El detalle final, un golpe de vista hacia el nuevo siglo, quisiera prever sensibles victorias contra algunos de los padecimientos que enunciamos hace ocho años en el prólogo a la antología Nuevos críticos cubanos, cuyos 
matices y máscaras, entre vaivenes, siguen siendo: «... contra los preceptistas, contra el academicismo moderado o el neopositivismo determinista; rechazar los matices contemporizadores, los ditirambos altisonantes, los denuestos y peroratas; repudiar la aceptación de errores ajenos, los equívocos que dimanan de la repetición confusa de fórmulas y conceptos tradicionales, las coerciones del raciocinio o las astutas cautelas.»

Todavía pensamos - sin alternativas remediales - que Susan Sontag exageró al pensar que cualquier interpretación de una obra artística no es más que un gesto de arrogancia. Aunque repitamos un lugar común de Fernando del Paso, cuando en una reciente entrevista en La Habana para el mensual El Caimán Barbudo, aseveraba: «Todos sabemos... que existe un exceso de crítica - la nueva crítica - y una pasión por ella -más intelectual que visceral - que ha dado como resultado que los estudiantes se acerquen primero a la crítica de un autor antes que a su obra.»El autor de Palinuro de México —sa deliciosa hipérbole del síndrome de Larousse, como diría Saul Bellow- añadía con astucia: «Se dan casos... de personas que han leído todo lo que se ha escrito sobre Cortázar sin casi haber leído al propio Cortázar.»

La inflación crítica, en particular la universitaria, frecuentemente da lugar a un homolenguaje insípido, dentro de los bostezos, simposios, ideas trilladas, homenajes, pedanterías, seminarios, criptologías, hemerografías y anuarios. Es sano anhelar que el curriculum vitae no se convierta en ridiculum vitae.

Otro anhelo es exaltar - antes o después de Barthes- el placer de leer, lo que quizá logre mejorar la llamada teoría (o teorías) de la recepción de base «gestaltista», a través de la jerarquización del lector y de la prioridad otorgada a los instrumentales de percepción y disfrute. La esperanza de ayudar a una «buena orientación», que considerara Pedro Henríquez Ureña como la primera condición del lector —como nos recordaba su hermana Camila en Invitación a la lectura y en sus inolvidables clases universitarias-, se nos hermana a las imprescindibles investigaciones de carácter sociológico sobre autor-obra-lector o sobre programas y textos de enseñanza de la literatura, carentes aún de una concepción sistemática y de una orientación cuyo objetivo central sea formar el hábito de lectura.

El detalle de la perspectiva - la ensoñación- tampoco puede desconocer la necesidad de equipos interdisciplinarios o de iniciar investigaciones comparatísticas. Puedo repetir las líneas finales del prólogo a Nuevos críticos cubanos, de diciembre de 1979: «Mientras pensamos acerca de la crítica literaria cubana del futuro, nos vienen a la mente la revolución científico-técnica, palabras como cibernética e informática, los valores éticos y científicos del trabajo en equipo... Quizá estemos ya en los albores 
de una ciencia de la literatura que verá el trabajo individual-aislado como vemos hoy la pintura rupestre.»

La perspectiva aspira a sistematizar como algo común la aparición de indagaciones valiosas, como la reciente reivindicación histórica del poeta romántico Juan Clemente Zenea, realizada por Cintio Vitier, o libros de la calidad de Hablar de la poesía, de Fina García Marruz; Cultura y marxismo, problemas y polémicas, de Desiderio Navarro, o la próxima aparición de Ensayos en el tiempo, de Enrique Sainz; Crítica de la razón poética, de Eduardo López Morales; Caminos actuales del teatro cubano, de Raquel Carrió; El cuento cubano: apreciaciones artísticas, de Salvador Redonet... Aspira a que labores como la que realiza el Centro de Estudios Martianos en la preparación de la edición crítica de José Martí o la recién terminada edición crítica de Paradiso, de Lezama Lima, no despierten asombros ni convoquen sorpresas. Anhela que la edición de Indices y textos de referencia bibliográfica no pierda sistematicidad y alcance mayor continuidad, o que antologías y valoraciones múltiples de autores, períodos, movimientos o géneros -como las que realiza la Casa de las Américas- logren un necesario auge, junto a una mejor y mayor publicación de textos teóricos y de información actualizada en general. Asimismo, que crónicas-críticas como las que escribe Luis Suardíaz y el llamado «periodismo literario» (recensiones, artículos por efemérides, etc.) obtengan más calidad promedio y más espacio en la prensa no especializada; también qu' algunos profesores universitarios de la calidad de Luisa Campuzano o investigadores valiosos, como el poeta Emilio de Armas, tengan una participación más frecuente en la valoración de nuestra literatura actual, tanto como jóvenes del talento de Teresa Fernández y Frank Padrón. Y que escritores que sólo incursionan esporádicamente en la crítica — la lista sería enorme - también brinden una colaboración menos circunstancial o de compromiso. Junto a un sentido ecuménico que comprenda la labor de aquellos autores no residentes en el país, como parte de aventuras y polémicas, que han dejado - dejan - una estela insoslayable, como el novelista Severo Sarduy (Escrito sobre un cuerpo, Barroco...), el dramaturgo José Triana (El estudio sobre la generación del 98...) o el poeta Emilio Bejel (Las indagaciones sobre Lezama Lima...). Y habría que recordar especialmente los textos de José Juan Arrom, de Eugenio Florit, de Roberto González Echevarría y de Enrico Mario Santí, entre los que más se destacan fuera de Cuba. La amplia nómina de autores y textos quizá sea el más contundente argumento contra nociones de indigencia. Si bien la literatura cubana actual no puede mostrar cumbres como Carpentier o Lezama, sí cuenta con un amplio grupo de autores a la altura de cualquier otra nación del idioma, dentro de los cuales el ejercicio de la crítica literaria, en sus 
diversas formas, no ha dejado de estar presente y de alcanzar relevancia internacional por encima de mil y un escollos.

El panorama podría completarse con una sutil advertencia de Ambrosio Fornet: «Lo extraño no es que falten críticas.» El crítico de En tres y dos, entre otras ingeniosidades y reticencias, hablaba de una poderosa «crítica oral» en talleres literarios, concursos, eventos y corrillos... Podríamos entender la «falta», fuera de «contexto», como una solicitud de motivaciones a la literatura. También podríamos intentar una explicación de lo que he llamado «eclecticismo discernido de hoy». Entenderlo como la confluencia crítica de disímiles instrumentales de análisis, sin desdeñar logros impresionistas o semióticos, sin dejar de estudiar a Carlos Marx o a Sigmund Freud, de leer a Derrida y a Lacan, a la Kristeva o a Gerald Price... De observar la escuela de Tartu o de Yale, el grupo de Lieja o de Francfort... Poner en crisis conceptos como el de lectura, signo, sujeto y representación no sólo estaban en camino en los escritos estructuralistas de los años sesenta - como sostiene Jonathan Culler-, sino que aparecen en las parábolas de Chuang-Tzu, si se me permite la ironía de una hipérbole. Markiewicz insiste en que la mayor cantidad de interrogantes se amontona en torno al concepto de «horizonte de expectativas». Habría que pensar, además, en la relación inversa entre cientificidad y pérdida de audiencia, recordar a los savonarolas y los calvinos de la estética y coincidir con Arturo Azuela en la necesidad de «discrepar para enriquecer la propia ideología y convivir con elegancia o, más importante aún, para enriquecer nuestra visión del mundo».

Como he escrito y dicho en varias publicaciones y eventos cubanos, exponerse a los riesgos de las polémicas forma parte consustancial de la labor crítica, tanto más como la necesidad de ilusiones e iniciativas y sobre todo de mejorar la relación estímulo-trabajo. Hay todavía quienes piensan el trabajo de escribir como el violín que el pintor Dominique Ingres o el físico-matemático Albert Einstein tocaban en sus ratos de ocio. De la crítica literaria pensarán, si acaso, que es el atril... La ilusión, bien histórica, es que no se trata ya de las discriminaciones de una de las burguesías más incultas y dependientes del planeta, sino de una mala herencia alimentada por absurdos idealismos y que debe ser barrida por el desarrollo educacional, por nuevas generaciones mucho más cultas, es decir, más inteligentes y sensibles que las nuestras, en un país que siempre encara el futuro con dignidad, con desenfado y valentía. La genealogía del socialismo radica en el amor a la libertad, al libre pensamiento y al progreso. Por ello desde nuestras mesas de escritura podemos combatir las imágenes del mundo basadas en el deseo de justificación, la hostilidad hacia lo verdaderamente innovador, talentoso y autóctono en la literatura, en la vida. 
Tal vez la coda al detalle de la perspectiva deba volver a los versos de Goethe que sirvieron de epígrafe. O con toda humildad recordar otras palabras suyas en el Viaje a Roma: «No he tenido un solo pensamiento completamente nuevo.» Quizá repetir con Borges, para evitar alguna sombra de arrogancia o de potestad sobre estos apuntes: «El diálogo tiene que ser una investigación, y poco importa que la verdad salga de boca de uno o de boca de otro.» Mejor es finalizar con el sentido orgullosamente ancilar donde se agrupa lo más valioso de las letras cubanas. Asidos de la aversión a lo irrecusable, dueños de un sentido dialéctico del devenir histórico, encaramos los escollos - $\tan$ diversos - sin nihilismos o asepsias, pensando, junto a José Martí, que el ejercicio del criterio es una sencilla contribución a un mundo mejor.

La Habana, agosto 1987. 
